\title{
PUBLIC POLICY AND AUTOMOBILE OCCUPANT RESTRAINT: AN ECONOMIST'S PERSPECTIVE
}

\author{
KENNETH E. WARNER \\ Department of Public Health Policy and Administration, School of Public Health, University of \\ Michigan, Ann Arbor, MI 48109-2029, U.S.A.
}

\begin{abstract}
Cost-benefit analyses (CBAs) of policies intended to increase occupant restraint in automobiles typically find that such policies generate social benefits that exceed social costs, often by a considerable margin. The analyses are incomplete, however, due to their inability to incorporate potentially important costs and benefits that are hard to measure and monetize. Furthermore, analyses fail to account for distributional and political considerations. Despite these limitations, the evidence produced by the occupant restraint CBAs tends to bolster the case of advocates of mandatory passive restraints and other restraint policies. Support for governmental involvement can also be found in economic theory, although the theoretical case is not necessarily compelling. The principal lesson of this review of economic analysis of the occupant restraint issue is that analysis can inform an injury policy debate, but it cannot provide conclusive answers, nor can it serve as a substitute for the political decision-making process.
\end{abstract}

\section{INTRODUCTION}

This paper examines the economic perspective on injury in the context of a case study of injury and public sector intervention to reduce it. The injury case is the death and disability resulting from motor vehicle accidents, the source of half of all unintentional injury fatalities [Smith, 1984]. The public sector intervention is the federal government's attempts to provide car passengers with effective occupant restraint. These attempts relate to both active and passive restraint systems, respectively the seatbelts currently found in virtually all automobiles, and passive belts and airbags. The intent of this paper is twofold: (1) to determine how economic analysis has been applied to elucidate the occupant restraint issue, considering the technical merits of such analysis and the policy implications and impact; and (2) to re-examine the economic theory rationale for governmental intervention in the concrete instance of a major injury policy debate.

\section{BACKGROUND}

Motor vehicle accidents (MVAs) are the nation's leading source of injury-related death and disability. Each year, MVAs will kill from 40,000 to 50,000 Americans and inflict injuries on an additional 4 to 5 million. The distribution of this burden is of particular concern, since motor vehicle injury victims are disproportionately the young. The motor vehicle death rate for persons 15-24 years old is twice the national average; the median age of MVA fatalities is 27 years. As a result, the number of life-years lost prior to age 65-some 1.7 million per year-is roughly comparable to the number of "preretirement" years lost due to malignant neoplasms, which account for eight times as many deaths [Robertson, 1983]. The tragedy of MVA injuries is compounded by recognition that motor vehicle accidents are the principal source of severe and permanent disabilities among young people.

The sheer magnitude of the mortality and disability toll of MVAs qualifies them as a significant public health problem. But the fact that has thrust them into the public policy arena is the avoidability of so much of the death and disability. Modifications of vehicles, highways and driver behavior each could reduce the toll substantially. A prominent case in point, widespread use of occupant restraint systems, could reduce the MVA death and disability toll by an estimated $25-50$ percent, the range reflecting varying assumptions about the technical effectiveness of restraint systems, their use by the driving public, compensatory risk-taking behavior [Wilde, 1982], and so on.

Effective occupant restraint could be achieved through two mechanisms, one relating to a change in occupant behavior, the other to modification of the vehicle. The latter 
entails installation of passive restraints - passive belts and air bags. ${ }^{*}$ The former involves getting people to use the seat belts available in virtually all cars. The problem is the low rate of voluntary seatbelt usage, generally observed to be in the range of 10-15 percent through the early $1980 \mathrm{~s}$, with the resultant gap between the potential and realized injury avoidance associated with occupant restraint systems. Absent the pervasive disregard for belts, the gap would be much smaller. While there might still be potential for additional avoidance of injuries, it is most unlikely that the clamor for passive restraint and mandatory belt use legislation would approach its current intensity.

Public policy concern with occupant restraint covers more than two decades. Frontseat lap belts were first installed as standard equipment in cars in 1964, when 14 states required them. By the late 1960s, lap and shoulder belts were required as standard equipment in all new cars sold in the U.S. In 1969, the National Highway Safety Bureau (the predecessor to today's National Highway Traffic Safety Administration, NHTSA) proposed the first in a long series of rulemakings requiring passive restraints in automobiles. The intervening 17 years are best characterized as a period of debate on the wisdom of such a policy, punctuated by a series of federal rulemakings requiring passive restraints, each (to date) followed by repeated implementation delays or rescissions. The current operative policy dates from July 1984, when the Department of Transportation reinstated the passive restraint rule, requiring that all new cars sold in the U.S. have passive restraints by 1990 . This ruling included the proviso that passive restraints will not be required if states covering two-thirds of the U.S. population pass mandatory belt use laws. As of June 1986, 28 states had adopted such laws.

With occupant restraint so long at the forefront of MVA policy consideration, it is not surprising that the issue has attracted the attention of policy-minded economists. The majority of economic analyses have taken the form of cost-benefit analyses (CBAs), studies addressing the question of whether the individual and social benefits of belt use (or mandatory passive restraints) outweigh the costs. While CBA has been in use for many years [Warner and Luce, 1982], the technique is in its ascendancy as a tool of policy analysis, particularly with regard to governmental regulation, and this undoubtedly prompted some of the CBAs in this area, especially in recent years. But application of CBA to restraint issues is also a natural analytical response to two features of the contemporary reality of restraint use, each of which contradicts the intuitive appeal of restraints: (1) the majority of drivers behave as if the costs of seatbelt usage exceed the benefits (i.e. they choose not to buckle up), despite the fact that the cost of a severe MVA injury would be enormous and buckling up is so simple; and (2) the principal arguments levied against the passive restraint rule, primarily by the automobile manufacturers, are that one technology - the air bag-would be too expensive, while the other-the passive belt-would not be utilized with sufficient frequency to justify its smaller incremental cost (i.e. occupants would disconnect their passive belts, thereby converting them into active nonrestraints). Each of these points leads to a natural inclination to study the facts of restraint costs and benefits.

In the context of the social policy debate on occupant restraint, the existence of the CBAs is quite appropriate. Less self-evident is the validity and usefulness of the CBAs and, more fundamentally, the appropriateness of the fact and nature of governmental involvement in the occupant restraint issue. With regard to the validity of the CBAs, one must examine the strengths and weaknesses of this analytical technique as it has been applied in this case study of injury prevention. The usefulness of the CBAs depends both on the studies' technical merits and on the political environment in which restraint policy decision making occurs. From an economist's perspective the appropriateness of governmental involvement in the restraint issue centers around basic principles of economic theory and their application in this instance.

The next section of this paper presents a brief discussion of the literature on CBAs on occupant restraint, identifying themes and then focusing on CBAs that have received

*Research is also underway to develop cars with more "forgiving" interiors and exteriors that would automatically protect occupants in serious crashes, independent of restraint use. We do not consider this approach to occupant safety in the present paper. 
considerable attention in the course of the government's recent deliberations on a passive restraint rule.* In the following section, the strengths and weaknesses of studies arc considered and their policy usefulness evaluated in the context of these technical aspects, as well as the context of the environment of restraint policymaking. The next two sections of the paper explore the broader issue of the appropriateness, and appropriate nature, of governmental involvement in this area of automotive safety. These two foci-a look at the substance and usefulness of occupant restraint CBAs and consideration of the theoretical basis of governmental intervention from the perspective of economics-lead to some concluding comments relating to the role of economic analysis in identifying and addressing major injury policy problems.

\section{CBAS OF MOTOR VEHICLE OCCUPANT RESTRAINT SYSTEMS**}

CBAs pertaining to the restraint issue date back a decade and a half. In 1970, Lave and Weber examined the costs and benefits of seatbelts from the perspective of the individual and found that benefits exceeded costs if the value of an individual's life was at least $\$ 10,000$, a number more than a full order of magnitude below the smallest estimates of the value of life (or livelihood). Lave and Weber failed to explain why, however, with benefits so much larger than costs, the majority of riders chose not to wear belts. Thaler and Rosen [1975] addressed this question in an analysis in which they compared the time costs of buckling up with the expected benefit. They estimated an annual benefit from wearing lap belts of approximately $\$ 10$ (using a value of life of $\$ 200,000$ ) and argued that the individual's opportunity cost of time involved in buckling and unbuckling the seatbelt could easily exceed this amount.

Analyses of a passive restraint rule followed shortly after the early examination of the economic merits of seatbelt use. These analyses fed directly into the policy debate on the wisdom of requiring passive restraints in all cars. In 1974, NHTSA released a CBA that demonstrated "the superiority of passive restraint systems compared to belt systems presently required." Two years later, another CBA accompanied the announcement of a public hearing to be held by the Department of Transportation (DOT) [Insurance Institute for Highway Safety, 1978]. At about the same time, Robertson [1977] directed a survey which, though not itself a CBA, produced a finding of direct relevance to CBA: a sample of new-car buyers expressed a willingness to pay an average of $\$ 12$ more per month ( $\$ 144$ per year) in car payments to save 6000 lives per year, and $\$ 17$ per month (\$204 per year) to save 12,000 lives. According to these figures, it appears that many new-car buyers might stand prepared to pay considerably more than the amount passive-belt systems would require. Of course, whether answers to a hypothetical question would translate into equivalent action in the marketplace remains to be seen.

Despite studies such as these, implementation of a passive restraint rule did not occur. Delays and rescission of the proposed rule (known as Federal Motor Vehicle Safety Standard, or FMVSS, 208) became particularly politicized during the Carter and Reagan administrations. In 1981, two CBAs gained considerable attention as they were developed by highly regarded economists and fed into the policy debate. In one study, authors Arnould and Grabowski analyzed the economics of the lap/shoulder belt from the perspective of the individual and, separately, passive-restraint systems from the point of view of society as a whole. In the first of these, Arnould and Grabowski worked with three different weighting schemes to value individuals' willingness to pay to avoid injuries of varying severity. The authors concluded that the expected annual benefits from regular belt use, $\$ 38$ to $\$ 78$ (in 1975 dollars), had to exceed the time opportunity costs associated with buckling up. Subject to two qualifications, which they dismissed as insufficent to

*It is assumed that the reader is familiar with both the basic principles of cost-benefit analysis and the rudimentary facts pertaining to occupant restraint systems. The reader who is not acquainted with CBA should consult Warner and Luce [1982], Mishan [1976], or any other introduction to the analytical technique. For background information on restraint issues, see Warner [1983].

${ }^{*}$ Material in this and the succeeding section reproduces or draws heavily from text in a previously published article by the author [Warner, 1983]. 
reverse their conclusion, they argued that belt nonuse is not the result of rational, informed decision-making, as Thaler and Rosen has suggested it to be. On the contrary, Arnould and Grabowski interpreted their findings as supporting the "insensitivity-to-low-probabilities" hypothesis. This hypothesis suggests that for very low-probability events, such as a serious car crash on a single outing, individuals become insensitive to the high potential cost of not protecting themselves, and indeed may not comprehend the meaning of the tiny probability; instead, they respond to the unlikelihood of the event. Furthermore, Arnould and Grabowski presented evidence that people significantly underestimate their risk of involvement in an automobile accident. (See, also, Kunreuther, 1985.)

While Arnould and Grabowski's evidence and logic are persuasive, they are not entirely convincing. One can argue, for example, that the authors dismissed too readily the possibility that people value freedom from the discomfort (physical or psychological) produced by belts at more than the expected benefits. Given hundreds of hours of driving per year, the hourly discomfort cost would have to be extraordinarily low for this factor not to play a role.

Arnould and Grabowski's second CBA, on mandatory passive restraints, concluded that a system of either automatic belts or air bags would produce substantial social benefits, with the benefits of airbags slightly exceeding those of automatic belts. The cost of the bags is so much higher than that of the belts, however, that belts appeared to be superior on the basis of net benefit (or benefit-cost ratio). Indeed, the authors found that only under very favorable conditions would airbags result in positive net benefits; in other words, the costs of bags quite likely would exceed the benefits. Again, however, Arnould and Grabowski ignored discomfort costs, which apply only to belts.

Arnould and Grabowski's study is noteworthy for its sensitivity analysis, which tests the impact of varying assumptions on the benefit-cost conclusions. The analysis is thorough in its consideration of economic costs and benefits, but it merely mentions the costs of inconvenience and discomfort associated with belts, costs which must be considered potentially large given all of the evidence on belt use; and, like almost all CBAs, the analysis ignores the costs of the suffering experienced by the loved ones of automobile accident victims. Subject to these limitations, the authors estimated that, in a steadystate situation (i.e. after passive restraints were in virtually all automobiles, commonly estimated to require about ten years), net benefits of passive belts could be as high as $\$ 8.5$ billion, and would not be likely to be less than $\$ 3.4$ billion, the range reflecting varying assumptions about rates of disconnecting passive belts and the like. Net benefits of air bags, by contrast, could reach $\$ 6.6$ billion, but could also be as low as $-\$ 4.9$ billion, the cost of bags being a significant variable. The authors also calculated expected annual costs per life saved, which ranged from $\$ 135,000$ to $\$ 557,000$ for belts, and from $\$ 472,000$ to $\$ 2,159,000$ for bags. These cost figures attribute no value to injuries avoided.

Another CBA was undertaken precisely to feed into DOT's reconsideration of FMVSS 208. Sponsored by five major automobile insurance companies, Nordhaus [1981] examined and compared the two passive-restraint systems, although he focused his analysis on passive belts, the system generally expected to dominate if FMVSS 208 were to go into effect. The analytical slant taken by Nordhaus was somewhat different from that of Arnould and Grabowski, since he concentrated on the (net) cost of delaying or reordering implementation of Rule 208, rather than making the "either-or" comparison of the status quo with a fully implemented passive-restraint rule. Of course, as one of DOT's options was to rescind Rule 208 altogether, Nordhaus's analysis of the net cost of this option is directly comparable to other analyses of the net benefit of fully implementing a passiverestraint rule. (See, also, Nordhaus, 1984.)

Nordhaus estimated that, in a steady state, the annual net cost of a rescission would equal $\$ 2.4$ billion, assuming that all cars would otherwise be equipped with automaticbelt systems. He derived this number using NHTSA and manufacturer data which he believed to be biased against the belt system; hence he viewed his estimate as a lower bound on the net benefits of passive belts. Under these conservative assumptions, the benefits of the system ( $\$ 3.6$ billion) are three times greater than the costs $(\$ 1.2$ billion). 
Nordhaus estimated the total discounted net social benefits of the passive-restraint rule at $\$ 33$ billion. Alternatively, $\$ 33$ billion represents the net cost to society of a complete rescission of the rule. Under the assumptions that he believed to be more reasonable, this figure rises to $\$ 69$ billion. Nordhaus summarized his finding as follows:

The passive restraint rule is, from an economic point of view, as important as any environmental, health, or safety rule on the books. If the estimates of the impact on fatalities are accurate, a rescission would be equivalent to repealing a law that cuts in half the homicide rate. It is equivalent to foregoing the medical advances that allowed the virtual elimination of death from tuberculosis over the last quarter century.

Nordhaus's CBA shares with Arnould and Grabowski's an effective use of sensitivity analysis. Unlike Arnould and Grabowski, Nordhaus found that a world of air bags would be preferable to a world of passive belts. Despite the then-high cost estimate he used to evaluate bags ( $\$ 425)$, Nordhaus concluded that an all-bag system would generate total discounted net social benefits of $\$ 47$ billion. He did not dwell on the comparison, however, since at the time of his study belts appeared to be the wave of a 208 future.

As part of his policy analysis, Nordhaus examined the impact on the automobile manufacturers of implementing Rule 208. The only major organized opposition to implementation of the Rule through the years, the manufacturers have expressed concern about the costs of adding passive restraints as standard equipment and what this would do to the demand for their product. The potential problem was of particular concern in the early $1980 \mathrm{~s}$, with the domestic industry in a depressed condition. Nordhaus presented a case that adverse effects would be minimal. He suggested that it is even conceivable that the industry would benefit from implementation of Rule 208. This would occur if consumers recognized the net economic savings involved in buying a passive-restraintequipped car, given an associated reduction in automobile insurance costs.

Graham, Henrion and Morgan [1981] have identified half a dozen other CBAs on the occupant-restraint issue and have produced a detailed analysis of their own, one which compares passive-restraint systems with other methods of encouraging restraint. Their analysis ranked FMVSS 208 below other alternatives in terms of both net benefits and benefit-cost ratio, with a compulsory belt-usage law having the highest ratio (in large part because its measurable costs are so low) and a combined air bag/mandatory-beltusage law producing the greatest net benefits (and saving the most lives). All of the alternatives they examined produce positive net benefits; that is, each is preferable to the complete absence of occupant restraints (and superior to the current system of merely requiring belts in cars). In particular, they estimated that the benefits of FMVSS 208 would exceed the costs by 95 percent.

While the vast majority of occupant restraint CBAs conclude that restraint systems and rules are economically desirable, all of the precise estimates are highly dependent on assumptions concerning restraint system usage, effectiveness when used, and the value attributed to the saving of lives [Graham and Henrion, 1984].

\section{ASSESSMENT OF THE OCCUPANT RESTRAINT CBAS}

The CBAs noted above and others constitute a body of economic evidence on the social desirability of the government's mandating use of seatbelts or the installation of passive restraints in all automobiles. These studies exhibit both significant consistencies and important differences. Among the latter are the following: some adopt a humancapital approach to valuing life (or livelihood), while others use willingness-to-pay [Warner and Luce, 1982]; basic data sources, and hence magnitudes, often vary significantly; restraint alternatives differ from one analysis to the next; some analyses incorporate concerns like the effect of restraint systems on insurance costs, while others ignore them; and so on.

Almost all of the studies can be faulted for their failure to treat analytically the 
inconvenience and discomfort costs which, though nonpecuniary, seem to play a significant role in many people's decisions about using manual belts. It may be difficult or unreasonable to place a dollar value on such costs directly. However, there are sensitivity analysis techniques that would permit an evaluation of the potential significance of these costs. For example, one might employ breakeven analysis to determine how highly people would have to value the inconvenience and discomfort in order to make passive belts appear to be socially undesirable [Warner and Luce, 1982].

Despite their idiosyncrasies and their individual and collective flaws, as a body the passive-restraint CBAs (the emphasis of recent analysis) present an impressive case that society would benefit more than it would lose from a compulsory passive-restraint rule. The findings are reasonably consistent and robust. In general, the studies rank air bags ahead of passive belts as life-saving devices, in large part reflecting the ability (and desire) of many owners of passive-belt-equipped vehicles to disconnect their belts. With some notable exceptions, the analyses rank belts higher than bags on cost-effectiveness and cost-benefit grounds, primarily reflecting the much lower cost of the passive-belt option; but, as discussed above, these studies ignore the nonpecuniary costs of discomfort and the like. While all of the studies find passive belts to produce positive net benefits (again, absent nonmeasured psychological costs), several of the analyses note that the net benefit of air bags is sensitive to changes in assumptions.

Despite the uniformity of these studies' findings, the analyses have articulate critics who challenge basic assumptions of the models. Industry critics argue that seatbelt cost estimates used in the analyses are too low; and they focus in particular on estimates of passive-belt use. The automobile industry seems convinced that incremental belt-usage rates would be extremely low, assuming passive belts that could be easily disconnected (a condition that they believe would be demanded by the public). Thus the industry views passive belts as increasing vehicle costs without significantly increasing effective passenger restraint [Martin, 1981]. Current (manual) belt users would thereby be "punished" by an unnecessary additional charge, while confirmed nonusers would have to bear the same additional burden but would realize no additional protection.

At the close of this brief overview of occupant restraint CBAs, one should keep in mind several caveats. First, a finding that mandatory passive restraints of either type would be cost-beneficial does not necessarily mean that such a mandate would be the most cost-beneficial approach to saving lives through occupant restraint. Other alternatives should be compared, in order to seek the approach that would maximize net social benefits. The most obvious alternative in today's legislative climate is mandatory belt use laws. Public education campaigns via the mass media and the schools constitute a second alternative. Combinations of efforts should also be considered (e.g. belt law plus mass media campaign).

Second, use of the phrase "net social benefits" suggests an important aspect, and limitation, of using CBA in a policy framework: as was noted at the outset of this discussion, measurable costs and benefits are not the only, nor necessarily the most important, variables in policy decision-making. Above, studies were faulted for their failure to value discomfort and inconvenience; on the other hand, none of the CBAs attempts to quantify the pain and suffering of accident victims and their loved ones. Thus the net social benefit (including the noneconomic desire to minimize human suffering) may extend well beyond the measurable net economic benefit. We return to the importance of this in the concluding section of the paper.

Third and finally, CBAs generally do not adequately address the issue of just who benefits and who loses: not everyone realizes a net gain from implementation of a passiverestraint rule, and it is of course this division that has made a (slow) horse race out of what appears on cost-benefit grounds to be a socially desirable objective. CBAs typically examine total social benefits and costs, thus making distributional issues moot. But distributional considerations often play central roles in policy debates and their resolution. Although it has been attempted only rarely, CBA can be adapted to incorporate political and distributional considerations [Luft, 1976]. 
In traditional economic theory the grounds for governmental concern with an issue fall into one of two categories: technical problems with the operation of the free marketplace (called market imperfections) and distributional and fairness problems (inequity). The latter reflects society's judgment that the efficiently functioning market produces a distribution of a good or service that is socially unsatisfactory. Historically, for example, we have been unwilling to leave the distribution of educational opportunity exclusively to the unfettered marketplace; more recently, such goods and services as medical care, food and housing have been added to society's list of "essentials" that should be made available, to some degree, to all of society's members.

Can governmental involvement in the occupant restraint issue be justified on equity grounds? Ex ante, it is difficult to imagine a reasonable equity argument, since the distribution of restraint is determined by individuals' decisions made at very low cost (essentially the time and discomfort costs associated with buckling up, since belts are available in virtually all cars on the road today). One might argue that the ex post distribution of injuries is inequitable, largely because so many of the injuries are avoidable, but this seems to draw more heavily on a notion of paternalism than inequity in its traditional meaning. In short, the equity case for governmental involvement in occupant restraint, as it is commonly understood in economic theory, is not compelling.

The more familiar justification for public intervention relies on the notion that the market has failed, in a technical sense, to produce the optimum utilization of restraint systems. Conventional sources of market failure (with common examples in parentheses) include the following: inadequately informed consumers (medical care), irrational economic behavior (drug addiction), too few buyers or sellers (hospital services), extreme economies of scale (public utilities), externalities (pollution) and the existence of a pure public good (national defense).

Few markets present the ideal characteristics of the economic paradigm of efficient competition; market imperfections are identifiable to some degree in virtually all markets. The important question is one of degree: Is (are) the market imperfection(s) of sufficent importance to warrant interference with the workings of the free market? The pragmatic answer itself requires a comparison of costs and benefits: Do the benefits of the intervention(s) in question, in "righting" the market imperfection wrong, outweigh the costs of the intervention(s), including any inefficiencies associated with the process of intervening [Wolf, 1978]?

The environment in which car occupants make restraint use decisions (the "market" here) exhibits elements of market imperfection in many areas. As noted above, people's understanding of the risks of driving unrestrained is poor; on surveys, respondents systematically underestimate their risk of having an automobile accident, while also underestimating the effectiveness of belts. Furthermore, a natural inclination to avoid contemplating disastrous fates may lead people to suppress concerns about driving safety, and therefore to behave irrationally with regard to restraint use. Evidence supporting the insensitivity-to-low-probabilities hypothesis provides an additional illustration of a knowledge and/or rationality problem.

Flaws in the competitiveness of the automobile market also introduce relevant market imperfections. While there are several major automobile producers, their number and the market shares of the top firm, the top three, etc., are such that the idealized fruits of a perfectly competitive supply may not always be realized. For example, the absence of air bags as optional equipment on many cars may reflect in part the imperfect competitiveness of the market. Thus people who would be willing to pay for air bags do not always have the option available. This problem is exacerbated by the apparent economies of scale in air bag manufacture and installation. Auto producers claim that the per unit costs of bags would fall precipitously if the demand for bags were in the many hundreds of thousands. In 1980, for example, General Motors estimated that the average consumer 
cost of an air bag would be $\$ 1100$ if 100,000 were produced and that it would fall to $\$ 650$ to $\$ 700$ if 400,000 were manufactured. Ford has estimated a 200 percent difference in per-unit manufacturer cost between producing 200,000 and 885,000 air bag-equipped cars [Warner, 1982]. Thus the potential bag purchaser's cost of acquiring this form of restraint system is highly dependent on whether a "critical mass" of car buyers is like-minded.

The principal market imperfection argument raised in favor of governmental concern with occupant restraint is the externality argument. Accidents and resultant injuries impose an economic burden on people other than those involved in the accidents. This results from pervasive insurance coverage. The medical bills of accident victims are covered predominantly by insurance (private and public insurance covers over 90 percent of hospital bills), so fellow policyholders and taxpayers bear the economic responsibility for caring for the victims of accidents. In the instance in which the victim was unrestrained, both the injury and its associated costs might have been avoided.

A second form of externality is a technological one relating to air bags. The majority of MVA injury victims are not the original purchasers of the cars in which they are injured. Consequently the failure of the original owners to purchase air bags deprives the second-hand owner (or other user of the car) of the protection afforded by air bags [Baker, 1979]. Since retrofitting a car to include a bag is today a very expensive proposition, second-hand owners could desire air bag protection at a price in excess of the original-equipment cost (depreciated) but less than the cost of retrofitting; i.e. they would rationally decide to drive without air bag protection while being willing to pay the depreciated cost of original equipment.

Externality arguments are appealed to most often, but some observers consider their use an instance of trying to rationalize something that the user desires for other reasons. In other words, it is not really the disseminated economic burden that causes people and their governments to advocate occupant restraint, though the federal and state governments in particular are acutely aware of the economic dimension (due to responsibility for Medicare and Medicaid, respectively). Rather, it is something else, something less readily justified in an economically and politically conservative environment. Put simply, it is a concern with the aggregate death and disability burden of avoidable injuries, a conviction that such avoidable damage is, simple, socially untenable. This attitude likely arises from a number of sources, including general concern for the public health and welfare and compassion for known victims of accidents and hence the desire to help prevent others from realizing the same fate.

At first blush, this motivation would seem to be divorced from economics. It is quite reasonable, however, to describe the motivation in economic terms, relying on the concepts of externality and public goods. Regarding the former, one can argue that both individual tragedies and the collective toll of automobile accident injuries impose an emotional burden on other members of society, not limited just to the family and friends of victims. For example, all of us suffer when we read in the paper about a 10 year-old child being thrown through a windshield and sentenced to a life as a quadraplegic.

The public goods argument is similar in nature, if somewhat different in emphasis. Here the concern is with the aggregate toll of MVA injuries representing a "public bad," and the sense that reducing the total would represent a public good, one that is not being achieved through individual decisions regarding use of restraints.

In both instances-the externality and public goods arguments-one can understand the basic logic and still be left with a disquieting taste. At one level, it is difficult to be entirely rid of the flavor of paternalism, the sense that governmental insistance on car occupants being restrained results from the conclusion that occupants do not behave as they "should" (i.e. as a "reasonable adult" would) and hence that they must be forced to do so. In a country dedicated to individual liberty, this is not a satisfying reason for public sector involvement. Indeed, in this context, many Americans will read "involvement" as unwarranted "intrusion."

Where does this leave us? Are the market imperfections alluded to sufficient to recommend governmental concern with occupant restraint, or is such concern simply an instance of well-intentioned Big Brotherism? This is both a conceptual and an empirical 
question. The empirical question is addressed by analysis such as the CBAs discussed above: Do the benefits of a particular governmental intervention (such as mandating passive restraints in all new cars) outweigh the costs? In the next section we examine this question further. At the conceptual level, the economic theory case for governmental concern with occupant restraint rests on the multiplicity of individually relatively minor market imperfections. That is, no imperfection by itself presents an overwhelmingly compelling case for governmental involvement, but the sheer number of deviations from the characteristics of an ideally functioning market presents a case that must be considered at least arguable. At its core, however, it may well be that the best case for governmental involvement resides in a kind of public-good notion that lies somewhat outside the domain of neoclassical economic theory, an appeal to the good of the community as being something greater than the sum of its individual parts [Beauchamp, 1984].

\section{THE FORM OF GOVERNMENTAL INTERVENTION}

Public sector involvement in the marketplace can take any number of forms, ranging from the simple provision of information to the production and distribution of a good or service. Economic theory can inform the debate on the optimal type of intervention, as well as the desirability of its fact. A review of the narket imperfections discussed in the preceding section suggests some guidelines appropriate to the occupant restraint case. First and foremost, the apparent existence of a substantial information deficit on the part of the public, likely mixed with a limited ability to contemplate the need for restraint in a wholly rational manner, emphasizes that government should be striving to educate the public on the need for and benefits of occupant restraint. This approach to a public health problem has a long and honorable tradition, ranging from traditional school health education to mass media campaigns to encourage smoking prevention and cessation. In the area of occupant restraint, government sponsored media campaigns have been undertaken and were long ago identified as the Reagan Administration's preferred approach. Evaluations of such campaigns, however, have not found that they produced signficant behavior change [Robertson, Kelley, O'Neill et al., 1974; Robertson, 1983]. Advocates have responded that previous campaigns have not been well designed, a response that proponents of a passive restraint rule consider a stalling tactic. Thus concept and pragmatics meet in an uncomfortable arena: theory calls for provision of information, but experience challenges the effectiveness of this strategy.

No tactic need be pursued in isolation. It is certainly conceivable that a well-designed information campaign might play an integral role in a governmental effort that also included more "aggressive" tactics. The collectivity of market imperfections identified in the preceding section seems to recommend that government use a carrot or stick to encourage the automobile manufacturers to move in the direction of installation of more passive restraints. The Administration's current proposal presents an interesting mix of carrot and stick in requiring the installation of passive restraints but providing an "out" if enough state legislatures can be encouraged to pass mandatory seatbelt use laws. Other tactics could include tax-system-based economic incentives to producers or consumers, such as tax credits for, respectively, producing or buying passive restraint equipped cars. Alternatively, encouragement or incentives could be directed at the insurance industry to develop rate structures that incorporate discounts for equipped cars (as is currently done by a few insurance companies) [Kunreuther, 1985].

\section{AUTOMOBILE OCCUPANT RESTRAINT: ECONOMIC THEORY AND} PRACTICE-FINAL THOUGHTS

The theory of public sector economics and the practice of cost-benefit analysis in the area of automobile occupant restraint raise an ambiguous and somewhat anomalous situation: it is impossible to assess whether they are consistent or inconsistent; as a result, it is impossible to conclude with certainty that governmental intervention in the occupant 
restraint matter is desirable (or not), at least as economic logic would define desirability. The problem is the following: consistency requires that a finding of positive net benefits in a CBA of a public sector initiative be associated with an intervention that is clearly justified on grounds of market failure. The reason for this is that a perfectly functioning free market ought to arrive at results that produce available net benefits. If net benefits can be attained by deviating from a market result, something must be imperfect in that market. Together, the theoretical and empirical evidence might therefore seem to support the appropriateness of governmental involvement in the restraint issue. But the matter is not quite this simple, because our review of conceptual considerations left us with an ambiguous reading of the theoretical justification of intervention, and the CBAs are flawed by what they do not (and perhaps cannot) measure-the time and especially psychological costs of buckling up for many occupants and the value of the pain and suffering associated with avoidable injuries. Inclusion of the latter in CBAs certainly would add to the apparent desirability of governmental encouragement of restraint use; inclusion of the former, however, would detract from it.

This last point raises an essential conclusion noted earlier that warrants reiteration here: people choose not to wear existing (active) seatbelts for a number of reasons, only some of which may represent true market failure (e.g. misinformation or understanding about the effectiveness of belts or the risk of injury). The others-inconvenience and the physical or psychological discomfort experienced by some-constitute very real costs of belt-wearing. Arnould and Grabowski acknowedged such costs but dismissed them as incapable of explaining the high rate of nonutilization of belts. A consideration of their benefit-cost calculus, however, suggests that discomfort costs, combined with time and inconvenience costs, can go a long way toward explaining much nonutilization. In the face of the authors' finding of positive net benefits to individual belt use, the fact that the vast majority of the public does not buckle up implies either the existence of a significant market imperfection (presumably relating to lack of knowledge or irrationality) or an incorrect cost-benefit calculation, most likely due to omission of some important cost(s) of wearing belts.

Economists' inability to measure and value nonpecuniary costs is reflected in a second form of omission in occupant restraint CBA: no major CBA has assessed the desirability of a restraint alternative that is center stage in the occupant restraint debate-a mandatory manual belt-use law (though Graham, Henrion and Morgan [1981] considered this option briefly). This omission is not an unmeditated chance happening. Rather, it represents a premeditated decision to avoid trying to apply $\mathrm{CBA}$ to a case in which the principal costs are not readily measurable and convertible into dollars and cents. This is clearly of consequence to the occupant restraint debate, since a major approach is being ignored in the formal analysis. And it represents a generalizable limitation, and lesson, of the application of formal CBA: the understandable inclination to study analytically manageable policy alternatives means that analytically "messy" but legitimate alternatives are at risk of being overlooked or downplayed. The same analytical factor translates into the dimunition of ethical and philosophical considerations. In the present instance, the overriding issue for many citizens-paternalism, the spector of Big Brother-has been ignored in the formal quantitative policy analyses.

Where does this leave us? An economic conservative would conclude, I believe, that there is a case for governmental involvement in the form of provision of information, perhaps through a number of educational efforts. The case for more aggressive intervention might be deemed more equivocal, at best. The public health professional (or the economic liberal), by contrast, could read the economic evidence as supporting intervention in the form of regulation. The formal CBAs do present a compelling case that the measurable benefits of a passive restraint rule (and likely a mandatory belt use law*)

*The readily measurable components of a mandatory belt use law are the benefits which, given similar use rates, would be comparable to those of passive belts. Measurable costs of use laws, by contrast, are small, barring an elaborate enforcement effort. 
outweigh measurable costs. Combined with an appeal to the notion of community interest-our collective social benefit from making a substantial dent in the highway death and disability toll-this analytical evidence constitutes a plausible case for the public sector role in occupant restraint.

The economic perspective offers one final essential insight that deserves emphasis for a group of health professionals concerned with injury prevention. The prevention of injuries is an economic activity which, like any other, demands resources that have valuable and valid alternative uses. As such, injury avoidance should be thought of in a cost-benefit framework, whether or not the formal analytics are actually carried out. Achieving reductions in the toll of injuries implies giving up something else-for example, giving up public health professionals' devotion of their time to encouraging a healthy diet. Thus, injury prevention should be sought only so long as the benefits of additional avoidance of injuries exceed the additional (or marginal) costs. In our all-too-real world, this means that the optimum level of injuries is most likely non-zero; that is, sensible social policy includes the notion of knowing when to stop seeking further gains in injury avoidance. In the present instance, the existence of many thousands of easily avoided MVA injuries suggests that the optimum level of injury prevention has yet to be attained.

Perhaps the most important lesson that can be drawn from this case study is that economic analysis exists in an environment in which complex social forces and concepts hold equal or greater sway. A technical weakness of the restraint CBAs is their inability to account adequately for costs and benefits that are at their core hard to quantify or monetize. An "environmental" weakness of CBA is that, even when technically perfect, it must yield to the often inexplicable vagaries of politics and social decision making.

\section{REFERENCES}

Arnould R. and Grabowski H. Auto safety regulation: an analysis of market failure. Bell. J. Econ. 12, 2748,1981 .

Baker S. Who bought the cars in which people are injured? An exploratory study. Am, J. Pub. Health. 69, 76$78,1979$.

Beauchamp D. Democracy and Public Health. Unpublished manuscript, Dept. Health Policy and Admin., School of Public Health, Chapel Hill, NC, 1984.

Graham J. and Henrion M. A probabilistic analysis of the passive restraint question. Risk Analysis 4, 25-40, 1984.

Graham J., Henrion M. and Morgan M. An analysis of federal policy toward automobile safety belts and air bags. Dept. Engineering and Public Policy and School of Urban and Public Affairs, Camegie-Mellon Univ., Pittsburgh, PA, 1981 .

Insurance Institute for Highway Safety, Background Manual on the Occupant Restraint lssue. IIHS, Washington, DC, 1978.

Kunreuther $H$. Incentives for improving driving behavior-Ex ante/ex post considerations. Human Behavior and Traffic Safey, L. Evans and R. Schwing, eds., Plenum Press, New York, NY, 1985.

Lave L. and Weber W. A benefitwcost analysis of auto safety features. Applied Econ. 2, 265-275, 1970.

Luft H. Benefit-cost analysis and public policy implementation: From normative to positive analysis. Pub. Pol. 24, 437-462, 1976 .

Martin D. Comments of General Motors Corporation regarding passive restraints (FMVSS 208). Docket 74* 14; notice 22, Dept. Transportation, Washington, DC, 1981 .

Mishan E. Cost-Benefit Analysis. 2nd ed. Praeger, New York, NY, 1976.

Nordhaus W. Comments of William Nordhaus on notice of proposed rulemaking on federal motor vehicle safety standards: occupant crash protection. Docket No. 74-14, notice 22, Dept. Transportation, Washington, DC, May $26,1981$.

Nordhaus $W$. Supplementing notice of proposed rulemaking on federal motor vehicle safety standards. Docket No. 74-14, notice 35, Dept. Transportation, Washington, DC, June 13, 1984.

Robertson L. Car crashes: Perceived valnerability and willingness to pay for crash protection. $J$. Community Health 3, 136-141, 1977.

Robertson L. Injuries: Catses, Control Strategies, and Public Policy. Lexington Books, Lexington, MA, 1983.

Robertson L., Kelley A., O'Neill B. et al. A controlled study of the effect of television messages on seat belt use. Amer. J. Pub. Health 64, 1071-1080, 1974.

Smith G. Unintentional injuries: Intervention strategies and their potential for reducing human losses. Prepared for the Closing the Gap Project, Carter Center, Emory Univ., Atlanta, GA, Aug. 1984.

Thaler R, and Rosen S. The value of saving a life: Evidence from the labor market. In Household Production and Consumption, Sudies in income and Wealth No. 40, N. Terleckyj, ed, Nat. Burtau of Economic Research, New York, NY, 1975.

Warner K. Mandatory passive restraints in automobiles; issues and evidence. Background Paper \#1 in U.S. Congress, Office of Technology Assessment. Technology and Handicapped People. U.S. Govt. Printing Office, Washington, DC, 1982 . 
Warner K. Bags, buckles, and belts: The debate over mandatory passive restraints in automobiles. J. Health Politics, Policy and Law 8, 44-75, 1983.

Warner K. and Luce B. Cost-Benefit and Cost-Effectiveness Analysis in Health Care: Principles, Practice, and Potential. Health Administration Press, Ann Arbor, MI, 1982.

Wilde G. The theory of risk homeostatis: Implications for safety and health. Risk Analysis 2, 209-225, 1982.

Wolf C. A Theory of "Non-Market Failure": Framework for Implementation Analysis. Rand P-6034. Rand Corp., Santa Monica, CA, 1978. 